\title{
Ketotifen in atopic asthma and exercise-induced asthma
}

\author{
I S PETHERAM, J MOXHAM, C W BIERMAN, M McALLEN, \\ AND S G SPIRO
}

From the Department of Respiratory Medicine, University College Hospital, London

\begin{abstract}
The efficacy of ketotifen, a tricyclic benzocycloheptathiophene derivative, was assessed in an outpatient clinical trial and in a group of 12 asthmatic subjects with exerciseinduced asthma. Subjects in the outpatient trial had mild asthma and consisted of two groups: a group of 24 atopic asthmatics with at least one positive skin test reaction and with an associated history of bronchial reactivity to at least one allergen; and a group of eight asthmatics with one or more positive skin prick tests but no bronchial reactivity to an allergen. Both groups $\vec{\bullet}$ took four weeks medication of ketotifen $1 \mathrm{mg}$ bd and placebo in a randomised double-blind $\stackrel{\infty}{\rightarrow}$ crossover study. There was no difference between ketotifen and placebo for any measurement made during the study and consequently no evidence of drug efficacy. The exercise study followed a standardised protocol and each subject took in random double-blind order, placebo, $1 \mathrm{mg}, 2 \mathrm{mg}$, and $4 \mathrm{mg}$ ketotifen two hours before exercise. There was no difference in the mean decreases in lung function from pre-exercise baseline values after three doses of ketotifen than $\stackrel{\mathbb{D}}{\circ}$ with placebo. Drug levels suggested ketotifen was well absorbed. It would appear that if given $\overrightarrow{\overrightarrow{0}}$ for a period of only four weeks ketotifen has no beneficial effects in the management of mild asthma, and that a single dose before exercise does not modify exercise-induced asthma.
\end{abstract}

Ketotifen, an orally active tricyclic benzocycloheptathiophene derivative, has several properties suggesting it might be useful in the management of asthma. ${ }^{12}$ It inhibits passive cutaneous anaphylaxis and has a mast cell stabilising effect. It is also a potent antihistamine specific for $\mathrm{H} 1 \mathrm{re}-$ ceptors with little anticholinergic activity and it raises intracellular cyclic-AMP levels by inhibiting phosphodiesterase. ${ }^{12}$

Ketotifen has been shown to be effective in preventing histamine-induced bronchospasm, ${ }^{34}$ aspirin and tartrazine-induced asthma, ${ }^{5}$ and as effective as disodium cromoglycate in controlling allergen-induced bronchospasm. ${ }^{3}$ Proof of its efficacy in preventing exercise-induced bronchospasm is confined to a single comparative study with cromoglycate which showed good protection in eight of 11 subjects. $^{3}$ Controlled trials assessing the value of ketotifen as prophylaxis for asthma in outpatients have given inconclusive results. It has been shown to be as effective as disodium

Address for reprint requests: Dr SG Spiro, Department of Respiratory Medicine, University College Hospital, London WC1E 6AU. cromoglycate in studies of three months ${ }^{6}$ and of $\underset{\infty}{\stackrel{0}{叉}}$ six months' duration, ${ }^{3}$ and superior to the anti- $\frac{0}{7}$ histamine clemastine. ${ }^{3}$ Other controlled out- 3 . patient studies have shown a small but significant $\delta$ advantage of ketotifen in larger doses over placebo in atopic adults ${ }^{7}$ and only a trend for improve- $\frac{\text { o }}{3}$ ment in children. ${ }^{8}$

We report clinical studies to assess whether ketotifen provides effective prophylaxis against $N$ spontaneous attacks of asthma in three groups of asthmatic patients: mild atopic asthmatics with at 0 least one positive skin prick test and a history of bronchial hyperreactivity to that allergen; mild asthmatics with one or more positive skin prick $\varrho$ tests (ie atopic) but no history of associated bron- $\Phi$ chial reactions; and another group with exercise- $\stackrel{?}{?}$ induced asthma as their main symptom.

\section{Methods}

OUTPATIENT STUDY

Thirty-two volunteers with mild asthma aged be- 8 tween 7 and 55 years were each studied for 10 응 
weeks as outpatients in a randomised doubleblind crossover trial. Mild asthma was defined as attacks of wheezy breathlessness on at least two days a week or effective control of such symptoms in the previous two months. Each subject had previously been shown to have variability of more than $20 \%$ in peak expiratory flow rate (PEFR) and forced expired volume in one second $\left(\mathrm{FEV}_{1}\right)$ but these measurements were at least $70 \%$ of predicted normal at the time of entry to the study. All subjects had at least one skin prick test reaction greater than $3 \mathrm{~mm}$ to a battery of common allergens. All were taking regular medication, either disodium cromoglycate or bronchodilator aerosol, or both. One patient took inhaled beclomethasone but no one was taking oral corticosteroids. Bronchodilator treatment continued as necessary. There were two treatment periods each of four weeks. The first period was preceded by a "run in" week in which cromoglycate was stopped, lung function was assessed, and diary cards started. At the start of the second week ketotifen $1 \mathrm{mg}$ capsules or placebo capsules twice daily were started. After four weeks of the first treatment period a week was allowed for "washout" of any possible beneficial effect then the alternative preparation was taken for a further four weeks. The subjects were assessed at the start of the study, at the end of the fifth week, and at the end of the tenth week. Each patient recorded morning and evening PEFR before bronchodilator, daily severity of asthma (scored from 0-10), total daily number of bronchodilator "puffs" needed, and whether other drugs were consumed. All side-effects were noted. At the end of the study each patient was asked to score each trial period thus: $1=$ very good, $2=$ good, $3=$ fair, $4=$ useless. Each patient was questioned about side-effects at the end of each treatment period.

\section{EXERCISE STUDY}

Twelve volunteers who had previously been shown

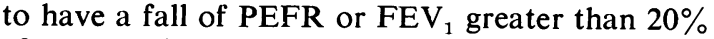
after exercise were tested on four separate occasions. They were exercised on a treadmill according to a standard protocol similar to that of Eggleston and Guerrant, ${ }^{9}$ so that heart rate reached $80 \%$ of maximum predicted during the last two minutes of the six-minute period of exercise. Bronchodilators or disodium cromoglycate were not taken for at least 12 hours before each study. Baseline lung function had to be within $10 \%$ of the values on the first study day on each subsequent study day. A single dose of ketotifen $1 \mathrm{mg}, 2 \mathrm{mg}, 4 \mathrm{mg}$, or placebo were taken in random order two hours before exercise. Peak expiratory flow rate, $\mathrm{FEV}_{1}, \mathrm{FVC}$, and expiratory flow at mid vital capacity (V50) were recorded 15 and one minute before exercise and at $0,3,5$, 10,15 , and 20 minutes after. The spirometer for measuring expired volumes and V50 was a dry wedge spirometer ("Floop" Oldelft, England Ltd). Venous blood for estimation of drug levels was drawn two hours (immediately before exercise) and three hours after ingestion. Plasma ketotifen concentrations were measured by radioimmunoassay.

Both studies were approved by the hospital ethics committee and the patients gave informed verbal consent for the outpatient study and written consent for the exercise protocol.

The data obtained from each study were analysed as group mean values by Student's paired $t$ test.

\section{Results}

\section{OUTPATIENT STUDY}

Thirty-two subjects entered the study but one dropped out at the start of the second trial period because of side-effects. The remainder were divided into two groups according to whether they gave a history of bronchial reactivity to at least one common allergen (group 1) or not (group 2). All subjects were skin test positive to the more common allergens - house dust mite, grasses, and various shrubs or flowers. Subjects allocated to group 1 either had a long standing history of bronchial reactivity to one or more of these allergens, or a positive history requiring medication within the last two months. Personal details of the two groups are shown in table 1 . Table 2 shows predicted values and measurements at entry to the study and four weeks after ketotifen and after

Table 1 Mean data ( $\pm 1 S D$ ) on entry to the outpatient study

\begin{tabular}{|c|c|c|c|c|c|c|c|c|c|}
\hline \multirow[t]{2}{*}{ Group } & \multirow[t]{2}{*}{ No } & \multirow{2}{*}{$\begin{array}{l}\text { Age } \\
(y r)\end{array}$} & \multicolumn{2}{|c|}{$\operatorname{Sex}$} & \multirow[t]{2}{*}{ Smokers } & \multirow{2}{*}{$\begin{array}{l}\text { No of attacks } \\
\text { per week }\end{array}$} & \multicolumn{2}{|c|}{ Regular treatment } & \multirow{2}{*}{$\begin{array}{l}\text { No of positive } \\
\text { skin tests }\end{array}$} \\
\hline & & & $M$ & $F$ & & & Cro & e Bronchodilator & \\
\hline 1 & 24 & $20 \cdot 7( \pm 6 \cdot 17)$ & 12 & 12 & 5 & $3 \cdot 7( \pm 3 \cdot 4)$ & 15 & 24 & $3 \cdot 7( \pm 2 \cdot 0)$ \\
\hline 2 & 7 & $42 \cdot 7( \pm 11 \cdot 3)$ & 5 & 2 & 2 & $7( \pm 9 \cdot 6)$ & 1 & 7 & $2 \cdot 6( \pm 1 \cdot 3)$ \\
\hline
\end{tabular}


Table 2 Mean values predicted lung function data $( \pm 1 S D)$ and values at the end of run-in period, the period on placebo, and the period on ketotifen. (Group 1, $n=24$; group 2, $n=7$ )

\begin{tabular}{|c|c|c|c|c|}
\hline & Predicted & Run-in & $\begin{array}{l}\text { Four-week } \\
\text { placebo }\end{array}$ & $\begin{array}{l}\text { Four-week } \\
\text { ketotifen }\end{array}$ \\
\hline \multicolumn{5}{|l|}{$F E V_{1}(l)$} \\
\hline $\begin{array}{l}\text { Group } 1 \\
\text { Group } 2\end{array}$ & $3 \cdot 36(0 \cdot 74)$ & $3.24(0.81)$ & $3.06(0.84)$ & $3 \cdot 12(0.82)$ \\
\hline $\begin{array}{l}\text { Group } 2 \\
F V C(l)\end{array}$ & $3.44(0.57)$ & $2 \cdot 19(0.51)$ & $2.35(0.39)$ & $1.88(0.79)$ \\
\hline Group 1 & $4.02(0.96)$ & $3.93(1 \cdot 11)$ & $3 \cdot 79(1 \cdot 15)$ & $3.92(1 \cdot 16)$ \\
\hline Group 2 & $4.28(0.65)$ & $3.24(0.89)$ & $3 \cdot 20(0 \cdot 98)$ & $2.91(1.05)$ \\
\hline \multicolumn{5}{|l|}{ PEFR (l/min) } \\
\hline Group 1 & $467(150)$ & $442(120)$ & $451(121)$ & $450(121)$ \\
\hline Group 2 & $532(85)$ & 331 (112) & 377 (107) & 348 (109) \\
\hline
\end{tabular}

Table 3 Mean data from diary cards ( $\pm 1 S D)$. (Group 1, $n=24$; group 2, $n=7$ )

\begin{tabular}{|c|c|c|c|c|}
\hline & Run-in & $\begin{array}{l}\text { Four-week } \\
\text { placebo }\end{array}$ & Washout & $\begin{array}{l}\text { Four-week } \\
\text { ketotifen }\end{array}$ \\
\hline \multicolumn{5}{|c|}{ Morning PEFR (l min) } \\
\hline $\begin{array}{l}\text { Group } 1 \\
\text { Group } 2\end{array}$ & $\begin{array}{l}414(86) \\
290(79)\end{array}$ & $\begin{array}{l}407(96) \\
298(76)\end{array}$ & $\begin{array}{l}401(105) \\
280(75)\end{array}$ & $\begin{array}{l}411(100) \\
272(79)\end{array}$ \\
\hline \multicolumn{5}{|c|}{ Evening PEFR (l/min) } \\
\hline $\begin{array}{l}\text { Group } 1 \\
\text { Group } 2\end{array}$ & $\begin{array}{l}453(75) \\
316(84)\end{array}$ & $\begin{array}{l}437(90) \\
317(88)\end{array}$ & $\begin{array}{l}422(109) \\
319(84)\end{array}$ & $\begin{array}{l}434(95) \\
301(86)\end{array}$ \\
\hline \multicolumn{5}{|c|}{ Mean asthma score $(0-10)$} \\
\hline $\begin{array}{l}\text { Group } 1 \\
\text { Group } 2\end{array}$ & $\begin{array}{l}2 \cdot 1(1 \cdot 6) \\
2 \cdot 5(1 \cdot 0)\end{array}$ & $\begin{array}{l}2 \cdot 1(1 \cdot 7) \\
2 \cdot 3(1 \cdot 4)\end{array}$ & $\begin{array}{l}2 \cdot 4(1 \cdot 7) \\
2 \cdot 4(1 \cdot 4)\end{array}$ & $\begin{array}{l}2 \cdot 0(1 \cdot 9) \\
2 \cdot 6(1 \cdot 1)\end{array}$ \\
\hline \multicolumn{5}{|c|}{ No of aerosol puffs/week } \\
\hline $\begin{array}{l}\text { Group } 1 \\
\text { Group } 2\end{array}$ & $\begin{array}{l}14 \cdot 2(20 \cdot 1) \\
30 \cdot 4(27 \cdot 7)\end{array}$ & $\begin{array}{l}13 \cdot 7(20 \cdot 2) \\
18 \cdot 9(19 \cdot 5)\end{array}$ & $\begin{array}{c}17 \cdot 9(21 \cdot 8) \\
8 \cdot 4(7 \cdot 1)\end{array}$ & $\begin{array}{l}13 \cdot 8(18 \cdot 0) \\
21 \cdot 8(20 \cdot 5)\end{array}$ \\
\hline \multicolumn{5}{|c|}{ No doses of other drugs } \\
\hline $\begin{array}{l}\text { Group } 1 \\
\text { Group } 2\end{array}$ & $\begin{array}{l}5 \cdot 7(11 \cdot 5) \\
7 \cdot 8(10 \cdot 8)\end{array}$ & $\begin{array}{l}3 \cdot 9(6 \cdot 8) \\
7 \cdot 6(9 \cdot 6)\end{array}$ & $\begin{array}{l}4 \cdot 5(7 \cdot 6) \\
6 \cdot 5(9 \cdot 0)\end{array}$ & $\begin{array}{l}2 \cdot 6(5 \cdot 4) \\
7 \cdot 8(9 \cdot 4)\end{array}$ \\
\hline \multicolumn{5}{|c|}{ Drug score $(1-4)$} \\
\hline $\begin{array}{l}\text { Group } 1 \\
\text { Group } 2\end{array}$ & & $\begin{array}{l}2 \cdot 76(1 \cdot 0) \\
3 \cdot 25(1 \cdot 0)\end{array}$ & & $\begin{array}{l}2 \cdot 5(1 \cdot 1) \\
3 \cdot 14(0 \cdot 9)\end{array}$ \\
\hline
\end{tabular}

placebo. Subjects in group 1 were younger, had more positive skin tests, and better lung function than group 2 on entry to the study. There was no significant difference in lung function measured after the trial period on placebo compared with ketotifen in either group 1 or group 2. On analysis of dairy cards (table 3 ) there was no evidence that ketotifen provided better control of asthma than placebo.

\section{EXERCISE STUDY}

Eight of the 12 subjects were male and the group had a mean age ( \pm SEM) of $27( \pm 2 \cdot 4)$ years. Mean values for measurements of lung function were similar before each test run (fig 1). There was no significant difference between the degree of fall in mean values of lung function with any dose of ketotifen compared with placebo (fig 1) nor in the time of the nadir for each measurement. The mean fall in PEFR, FEV 1 and V50 after the placebo runs were $45 \%, 33 \%$, and $55 \%$ respec $\stackrel{\vec{F}}{\stackrel{F}{+}}$ tively. Inspection of individual tests suggested tha? two patients had a small degree of protection from post-exercise bronchoconstriction but this was no民 statistically significant. Mean concentrations of drug in venous blood are shown in fig 2 .

Drowsiness was noted by three subjects in the exercise study with the $4 \mathrm{mg}$ preparation andsevere drowsiness was responsible for one patientw dropping out of the outpatient study.

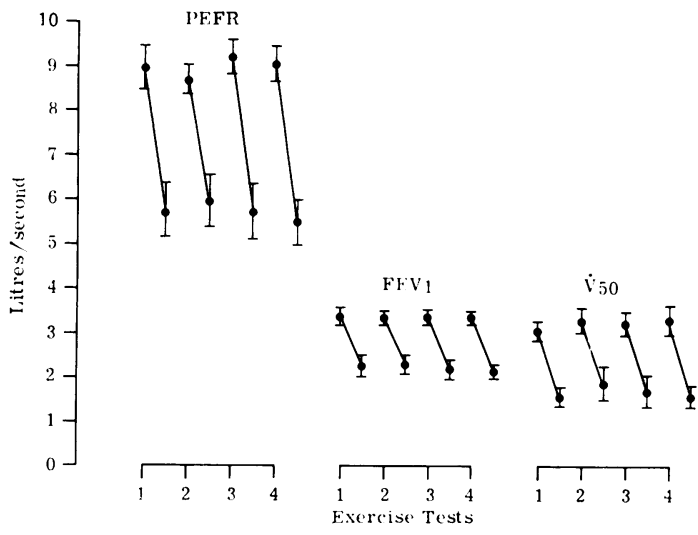

Fig 1 Group mean values for PEFR, FEV ${ }_{1}$, and $\checkmark 50$ before and after exercise tests. $1=$ placebo, $2=1 \mathrm{mg}, 3=2 \mathrm{mg}, 4=4 \mathrm{mg}$ ketotifen.

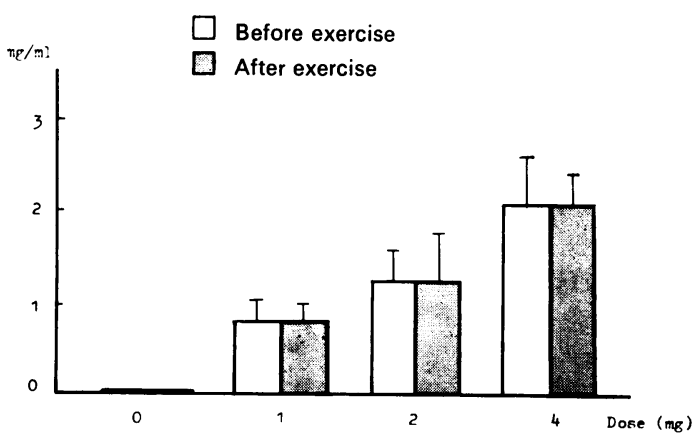

Fig 2 Group mean values ( $\pm 1 S D$ ) of plasma ketotifen concentrations for three doses and placebo.

\section{Discussion}

Effective prophylaxis against allergen-induced asthma and exercise-induced bronchospasm can be obtained from inhalation of disodium cromoglycate. ${ }^{1011} \mathrm{~A}$ drug with similar properties could be a useful addition to currently available asthma medication if it provided comparable prophylaxis, particularly if effective when taken orally. The 
pharmacological properties of ketotifen ${ }^{2}$ suggest it could be valuable in the management of asthma, and it has been shown to be as effective as disodium cromoglycate in controlling asthma in doubleblind studies of three months' ${ }^{\prime}$ and six months' duration. ${ }^{3}$ However, we have found no evidence from our studies that the drug provides effective prophylaxis against spontaneous attacks of asthma in outpatients nor protection against exerciseinduced bronchospasm.

Considerable problems exist in designing a trial to assess effective long-term prophylaxis in asthma. The duration of the study is probably important. A consistent trend in favour of ketotifen which failed to reach levels of significance was found in a three week double-blind crossover trial against placebo in asthmatic children. ${ }^{8}$ In a four week study only the higher dose of $2 \mathrm{mg}$ bd caused a slight but significant reduction in salbutamol usage and a modest improvement in breathing in patients not already receiving inhaled corticosteroids. $^{7}$ Subjective and objective evidence of improvement on ketotifen compared with clemastine was described in a double-blind parallel group study in adults followed for six months ${ }^{3}$ and in another six-month placebo-controlled study. ${ }^{12}$ Carrasco and associates ${ }^{13}$ report a significant progressive improvement between the first and third months of treatment in symptom scores, lung function, and withdrawal of concomitant medication in a three-month controlled study of atopic asthmatics. Both these latter studies suggested that improvement may only be obvious after one month's therapy and further studies should therefore be of longer duration.

Another problem is selecting patients who are sufficiently symptomatic to allow the drug to show its value. We deliberately selected patients referred to an asthma clinic with mild symptoms as these were considered most likely to benefit from a prophylactic agent. Despite stopping previous prophylactic therapy the mean values for lung function data after the four week placebo and active periods did not change and bronchodilator usage was not reduced. However, all subjects were atopic and three-quarters gave a good history of bronchial reactivity to inhaled allergens. Their severity of asthma and bronchodilator usage was similar to or greater than patients in comparable studies with ketotifen. ${ }^{7}$ Despite this ketotifen was not better than placebo. Failure to demonstrate beneficial effect cannot be accounted for by inadequate assessment since all patients kept detailed daily records of symptoms, PEFR, concomitant medication, and subjective treatment preferences- methods superior to occasional lung function testing. ${ }^{14}$

Exercise-induced bronchoconstriction is probably caused by hyperventilation, ${ }^{15}$ although exact mechanisms are still ill-defined. Since disodium cromoglycate provides effective protection in most patients who wheeze after exercise, release of cell mediators such as histamine, seem to play a part. Ketotifen, therefore, might be expected to show similar protection. Despite adequate and stable blood levels at the time of exercise challenge, ketotifen even in highest dosage showed no advantage over placebo. In an open study of asthmatic subjects treated for three days before exercise, oral ketotifen ( $2 \mathrm{mg} /$ day) was about as effective as inhaled disodium cromoglycate $(80 \mathrm{mg} /$ day) in blocking exercise-induced asthma. ${ }^{3}$ However, the advantage of disodium cromoglycate is that inhalation of one or two capsules just before exercise blocks bronchospasm effectively. Ketotifen ingested two hours before exercise challenge failed to show similar protection although our study did not compare it with disodium cromoglycate.

We are most grateful to Sandoz Products Ltd for provision of the trial capsules, to $\mathrm{Mr}$ A Cobley for technical assistance, and to Sister M Barker. Miss Angela Betchley typed the manuscript with great care.

\section{References}

1 Martin U, Römer D. Ketotifen: a histamine release inhibitor. Monogr Allergy 1977; 12:145-9.

2 Martin U, Römer D. The pharmacological properties of a new orally active antianaphylactic compound: ketotifen, a benzocycloheptathiophene. Arzneim Forsch 1978; 28:770-82.

3 Craps L, Greenwood C, Radielovic P. Clinical investigation of agents with prophylactic antiallergic effects in bronchial asthma. Clin Allergy 1978; 8:373-82.

4 Mattson K, Poppius H, Nikander-Hurme R. Preventative effect of ketotifen, a new anti-allergic agent, on histamine-induced bronchoconstriction in asthmatics. Clin Allergy 1979; 9:411-6.

5 Wuthrich B. Protective effect of ketotifen and disodium cromoglycate against bronchoconstriction induced by aspirin, benzoic acid or tartrazine in intolerant asthmatics. Respiration 1979; 37: 224-31.

6 Szczeklik A, Czerniawska-mysik G, Adamekgusik T, Koterba A. Ketotifen versus sodium cromoglycate in the therapy of allergic (extrinsic) bronchial asthma. Respiration 1980; 39: Suppl 1; 3-9. 
7 Dyson AJ, Mackay AD. Ketotifen in adult asthma. Br Med J 1980; 280:360-1.

8 Taylor B, Ford R. Ketotifen in childhood asthma: a double blind placebo controlled study. Clin Allergy 1979; 9:241-3.

9 Eggleston P, Guerrant JL. A standardized method of evaluating exercise-induced asthma. J Allergy Clin Immunol 1976; 58:414-25.

10 Brompton Hospital/MRC Collaborative Trial. Long term study of disodium cromoglycate in treatment of severe extrinsic or intrinsic bronchial asthma in adults. $B r$ Med $J$ 1972; 4:383-8.

11 Davies SE. The effect of disodium cromoglycate on exercise-induced asthma. $\mathrm{Br}$ Med J 1968; 3: 593-4.

12 Goebel P. The protective effect of ketotifen in 을 bronchial asthma. J Int Med Res 1978; 6:79-85.

13 Carrasco E, Galleguillos F, Bernath Z. Preven- $\stackrel{\odot}{\circ}$ tion action of ketotifen (Zaditen) in chronic@ perennial asthma. International Congress of Allergology, Jerusalem, 1979. Abstracts p 45.

14 Godfrey S. In: Clark TJH, Godrey S eds. Asthma. London: Chapman and Hall, 1977:272.

15 McFadden ER, Ingram RH. Exercise-induced asthma. Observations on the initiating stimulus. $\times$ $N$ Engl J Med 1979; 301:763-9. 